\title{
RECURSOS SOCIAIS E SELEÇÃO POLÍTICA: CHANCES DE INGRESSO EM DISPUTAS ELEITORAIS NO RIO GRANDE DO SUL ENTRE 1998 E 2006
}

\author{
Rodrigo da Rosa Bordignon ${ }^{1}$
}

Resumo: A presente proposta resulta do aproveitamento parcial de uma pesquisa, realizada anteriormente, sobre as relações entre recursos sociais e as diversas modalidades de ingresso na concorrência eleitoral. Os resultados mais gerais do conjunto de dados analisados no estudo principal apontam para uma associação entre posição social, estrutura do espaço partidário-eleitoral e trajetos que conduzem a condição de candidato em eleições gerais. Neste texto ora proposto, são analisadas, especificamente, as relações entre determinados recursos de posição social e as diferentes chances de participação eleitoral na condição de candidato aos cargos de deputado federal e estadual no Rio Grande do Sul, no período entre 1998 e 2006. Deste modo, estão em pauta as condições sociais de participação na concorrência eleitoral e de inserção em um espaço de atividades ao encargo de agentes especializados. Com isso, serão expostos os mecanismos sociais de seleção de candidatos a cargos legislativos e o conjunto de princípios de hierarquização e classificação social que se estendem à concorrência eleitoral.

Palavras-chave: Recursos sociais, Seleção de candidatos, Categorias socioprofissionais, Titulação escolar

Resumen: El presente trabajo es resultado del aprovechamiento parcial de una investigación, realizada anteriormente, a respecto de las relaciones entre los recursos sociales y las diferentes modalidades de entrada en la competición electoral. Los resultados más generales del conjunto de datos, analizados en el estudio principal, apuntan a una asociación entre posición social, estructura del espacio partidario-electoral y trayectos que lleven la condición de candidato en elecciones generales. Así, en el texto propuesto, son analizadas, específicamente, las relaciones entre establecidos recursos de posición social y las distintas oportunidades de participación electoral en la condición de candidato a los cargos de diputado federal y estadual en Río Grande del Sur, en el período entre 1998 y 2006. En consecuencia, están en juego las condiciones sociales de participación en la disputa electoral y de inserción en un espacio de actividades al encargo de agentes especializados. Por lo tanto, serán expuestos los mecanismos sociales de selección de candidatos a cargos legislativos y el conjunto de principios de jerarquización y clasificación social que se extienden a la disputa electoral.

Palabras-clave: Recursos sociales; Selección de candidatos; Categorías socio profesionales; Titulación escolar

Abstract: Present the proposal results previously of the partial exploitation of a research, accomplished, on the relations between social resources and the diverse modalities of ingress in the electoral competition. The results most general of the data set analyzed in the main study point with respect to an association between social status, structure of the partisan-electoral space and passages that lead the condition of candidate in general elections. In this proposed text however, they are analyzed, specifically, the relations between the determined resources of social status and different possibilities of electoral participation in the condition of candidate to the positions of representative and state in the Rio Grande do Sul, the period between 1998 and 2006. In this way, they are in guideline the social conditions of participation in the electoral competition and insertion in a space of activities to the charge of specialized agents. With this, the legislative positions and the set of beginnings of hierarchization and social sorting will be displayed the social mechanisms of selection of candidates that are extended to the electoral competition.

Key-words: Social resources, Selection of candidates, Socio-professional categories; University titres

\footnotetext{
${ }^{1}$ Doutorando em Ciência Política - IFCH/UFRGS.

Uma versão preliminar deste texto foi apresentada no III Seminário Nacional de Sociologia e Política da UFPR.
} 


\section{INTRODUÇÃO}

O problema geral abordado neste trabalho circunscreve as relações entre recursos de posição social e as diferentes chances de atuação como candidato em eleições gerais. Em termos mais específicos, trata-se de apreender o peso das categorias socioprofissionais da origem e da titulação escolar nas diferentes possibilidades de inserção na concorrência pelos cargos de deputado federal e estadual, no Rio Grande do Sul, no período entre 1998 e 2006. Partindo disso, o objetivo mais geral reside na problematização de algumas questões referentes às relações entre recursos de posição social e o ingresso no espaço de concorrência eleitoral.

As associações entre posição social e o espaço de concorrência eleitoral apontam para a elevação dos critérios de "entrada" na medida em que os cargos em disputa são hierarquicamente mais elevados (CORADINI, 2010). Igualmente, a progressiva objetivação da concorrência eleitoral implica uma diversificação dos recursos de legitimação de candidaturas, dentre os quais se pode destacar a recorrência cada vez maior ao "capital associativo" (CORADINI, 2001, 2007). Em geral, ao se relacionar a titulação escolar e as categorias socioprofissionais de origem com as possibilidades de ingresso na concorrência pelos cargos de representação política, percebe-se que as chances de atuação nestas lutas aumentam na medida em que sobe na hierarquia social. As implicações analíticas destas constatações retomam as questões relativas ao processo de autonomização do espaço político e de sua respectiva objetivação em termos de critérios de entrada e reprodução.

Este problema das relações entre recursos de posição social e as chances de ingresso na concorrência eleitoral se insere em um conjunto de controvérsias mais gerais, as quais estão na base das diferentes abordagens das ciências sociais acerca do recrutamento e seleção de elites políticas. Como se sabe, as diferentes modalidades de apreensão desses e de outros problemas dependem, por sua vez, de condições sóciohistóricas concretas e do distanciamento entre os problemas analíticos e a problemática política dominante (LACROIX, 1985, LÖWI, 1994, SAWICKI, 1999). No que tange especificamente aos interesses deste trabalho, é possível indicar dois conjuntos de dificuldades implicadas na apreensão dos condicionantes sociais de candidaturas e nos diferentes usos das "classificações sociais" frente ao espaço de concorrência políticoeleitoral.

Por um lado, estão em pauta as diferentes associações entre a "profissão" e/ou a condição social de origem e a "entrada na política”. Em geral, as discussões de fundo acerca destes problemas retomam aos diferentes usos e apreensões das análises de Weber sobre as relações entre determinadas profissões e o processo de 
"profissionalização” em política. De acordo com estas abordagens, as possibilidades de ingresso e dedicação à política variam relativamente ao "tempo livre" e as afinidades entre a "profissão" de origem e a "profissão política" (WEBER, 2003). Evidentemente, estas formulações podem favorecer um alto grau de deducionismo, principalmente em um contexto como o brasileiro, no qual os esquemas analíticos das ciências sociais são frutos de práticas de importação e tendem a instrumentalizar, explicita ou implicitamente, as tomadas de posição políticas (CORADINI, 2009). Contudo, a incidência destes problemas nas análises do recrutamento político não são uma particularidade brasileira e os contrabandos entre "o mundo da política" e os "objetos da ciência" estão diretamente associados ao atendimento de expectativas sociais e políticas implicadas neste tipo de estudo (OFFERLÉ, 1999). Além disso, a desconsideração do contexto histórico no qual e para o qual são formuladas estas apreciações, sobre as condições sociais que favorecem a atuação política, tende a tornar universalizável uma situação historicamente situada.

Como já evidenciado por outros estudos (CORADINI, 2001), o ingresso na "política" pressupõe uma ruptura com a "profissão" de origem e, muitas vezes, sua negação. Isso ocorre porque a ambivalência da tarefa de representação frente à esfera política implica em um processo de negação da contingência profissional e na posterior reconstrução desta relação com base em outras lógicas de atuação, notadamente fundadas na "liderança", cujo princípio remete à conquista do reconhecimento e à adesão de apoios. Ou seja, por um lado a representação política está associada às operações de crédito que tornam esta forma de dominação operante, e que dependem da posse de determinados recursos sociais objetivamente reconhecidos enquanto tais (AGRIKOLIANSKY, 1994). Por outro, as representações sociais, que são o fundamento dos princípios de legitimação de determinados "atributos", "títulos" ou, mais genericamente "categorias de classificação social", notadamente frente à esfera de concorrência eleitoral, dependem, diretamente, da força social dos agentes que os detêm e das estratégias e lutas por sua valorização e representação (BOLTANSKI e BOURDIEU, 2007, BOURDIEU, 2007c). Isso, inclusive, tem implicações nas diferentes possibilidades de reconversão desses recursos em trunfos nas disputas eleitorais e na entrada e carreira política (CORADINI, 2006).

Portanto, nessas relações entre "profissão" e/ou condição social de origem e a "entrada na política” estão em pauta os significados sociais de determinadas "categorias”, "atributos" ou competências em contextos históricos e políticos específicos (OFFERLÉ, 1999, 1996; LÉVÊQUE, 1996). Do mesmo modo, trata-se de levar a sério o trabalho social de intervenção e redefinição dos critérios de entrada e reprodução, os quais apontam para determinados processos históricos e concepções de "sociedade" e 
de "política” específicos (ver, especialmente, DULONG, 1999; DÉLOYE, 1999; WILLEMEZ, 1999). A principal implicação metodológica destas observações é que se devem considerar as informações apreendidas com base nos dados oficiais sob um duplo registro. Melhor dizendo, estes devem ser tomados tanto como indicadores de recrutamento e seleção de elites políticas, quanto como base de recursos sociais e princípios de legitimação de candidaturas, o que leva a não excluir das análises as finalidades práticas de produção e divulgação dos registros em pauta (ZARCA, 1993; MERLLIÉ, 1983). Isso ocorre por que as categorias de classificação que se expressam por meio das condições ocupacionais de origem são partes nas lutas eleitorais e operam como modalidades de apresentação e de autodefinição de uma posição social, acionando o conjunto de representações sociais correlatas a ela.

Outra das controvérsias presentes nos estudos de recrutamento político, que interessa diretamente a este trabalho, é aquela relativa ao peso da titulação escolar na hierarquização social. Os processos históricos e sociais que estão implicados na progressiva especialização de agentes sociais na luta política podem ser evidenciados, principalmente, pelo distanciamento da "condição profissional de origem" (ou até mesmo sua negação), pelos usos do tempo e dedicação à "atividade política”, e pelo monopólio dos postos de poder político nas mãos dos profissionais (OFFERLÉ, 1999, p. 11-7). Além disso, como demonstram estudos de recrutamento legislativo de longa duração (BEST e GAXIE, 2000), a objetivação da representação política pode ser evidenciada pelo progressivo fechamento deste espaço de atuação, o qual se expressa na exigência, cada vez mais elevada, da titulação escolar como princípio de legitimação e condição de entrada na carreira política.

Nestes termos, a autonomização, relativa da esfera política, se expressa no domínio de uma competência específica e na objetivação de uma atividade que têm em si sua própria finalidade, qual seja, a conquista dos lucros por meio da conquista dos postos do poder político. Portanto, assim como os diversos domínios de atividades especializadas, a "política" impõe seus modos de apreensão legítimos acionando determinadas disposições ou competências. Mais especificamente, as chances de reconhecer determinadas questões ou problemas como de "ordem política" requer determinados esquemas de percepção, que variam de acordo com a desigual distribuição dos "instrumentos materiais e culturais necessários a participação ativa na política", ou seja, a "intenção política só se constitui na relação com um estado do jogo político" (BOURDIEU, 2007a, p. 164)

Com base nisso, a variação do discernimento e dos usos sociais da relação com a "política" instituída é correlata à distância do espaço de produção de "bens políticos". Logo, os processos de divisão do trabalho político e as implicações objetivas da 
constituição e especialização de um domínio específico da vida social pesam nas interações entre os agentes sociais e a "política" (LACROIX, 1985, GAXIE, 1987, BOURDIEU, 2007b). Quer dizer que a objetividade do "campo político" implica um distanciamento objetivo em termos de critérios de entrada e uma objetivação das representações e princípios de hierarquização que são o fundamento de legitimidade da ocupação de determinadas posições.

Sendo assim, como demonstrado por alguns estudos (GAXIE, 1987; BOURDIEU, 2007b), as diferenças da relação com a política aparecem na desigual distribuição dos recursos sociais que estão na base dos processos de investidura e de reconhecimento de uma "competência” específica a determinados agentes sociais. A "competência política" é correlata à posição na hierarquia social e se traduz em um tipo específico de "competência social", fundada tanto em uma dimensão "técnica" quanto no "valor simbólico" de determinados títulos escolares, capaz de investir àqueles que se investem dela de um direito estatutário sobre as "questões políticas". Portanto, não se trata de uma relação intrínseca entre o conteúdo do aprendizado escolar e a "atividade política", e sim da objetivação de uma modalidade de "competência social" que depende, por um lado, das condições objetivas de seu exercício e legitimação e, por outro, do conjunto de disposições que são operantes e incidem nas possibilidades de relação com a política.

A partir disso, define-se a principal hipótese de trabalho, segundo a qual, "só entram em competição [pelos postos de poder político] aqueles que, pelo fato dos recursos que são capazes de mobilizar na disputa, estimam ter chance de sair vitoriosos" (LACROIX, 1985, p. 532). Melhor dizendo, as chances de entrada na "carreira política", as quais estão associadas às chances diferenciais de "entrar" na competição pelos postos de poder político, tendem a circunscrever as lógicas de “seleção social” (GAXIE, 1980, 1983, 1987).

Deste ponto de vista, a análise das relações entre agentes sociais e a "política" instituída deve tomar como ponto de partida a atividade de "empresário político" a partir das "condições efetivas nas quais ela aparece" e das "modalidades efetivas sobre as quais se realiza" (LACROIX, 1985, p. 537). Portanto, trata-se de tomar o problema da autonomia do "campo político" a partir de seu processo de objetivação social, ou seja, como evidenciação da realidade prática de um domínio específico de atividades que estrutura interesses e investimentos e "tem podido se impor, se perpetuar e ter seus efeitos" (idem, p. 477). 


\section{DADOS DISPONÍVEIS E CONSIDERAÇÕES METODOLÓGICAS}

O objetivo central do presente texto reside na evidenciação das relações de determinados recursos de posição social e as chances de atuação como candidato em disputas eleitorais. Nesta perspectiva, a sociografia entra como modo de apreensão dos mecanismos sociais presentes na seleção de candidatos e busca explicitar as relações entre estrutura social e participação eleitoral. Portanto, os indicadores de posição social entram para a definição da estrutura do espaço social e sua relação com o espaço de concorrência eleitoral. Ou seja, ao se colocar em relação a estrutura de posições sociais com as chances de participação eleitoral, pretende-se apreender os fatores sociais que estão na base das distorções que separam os "profissionais" dos "profanos" e que fundamentam as diferentes relações com a "política” instituída (BOURDIEU, 2007b; GAXIE, 1980, 1987; LACROIX, 1985).

Com esse objetivo, foram confrontadas as informações obtidas a partir do exame dos registros de candidatura disponíveis no arquivo do Tribunal Regional Eleitoral do Estado do Rio Grande do Sul (TRE-RS) com os microdados do Censo de 2000 e da Pesquisa Nacional de Amostra de Domicílios (PNAD) de 2002. Mesmo com todas as implicações decorrentes da utilização de um material empírico, produzido com base em diferentes "princípios classificatórios" e "razões de ser" (MERLLIÉ, 1996), é possível apreender os significados sociais de determinadas classificações ocupacionais com base no conjunto de recursos que as definem e diferenciam, notadamente, rendimentos econômicos e titulação escolar.

Para isso, as classificações ocupacionais presentes nos registros de candidatura e aquelas disponíveis no Censo e na PNAD foram padronizadas com base em critérios específicos. Considerando a heterogeneidade das categorias socioprofissionais de origem presentes nos registros de candidatura $^{2}$, estas foram classificadas em 15 agrupamentos ocupacionais ${ }^{3}$. A classificação e agregação das informações em categorias fundamentaram-se, basicamente, em três critérios: 1) a competência técnica requerida para o exercício de determinada atividade; 2) similaridade de atividades; 3) e relações com a divisão social do trabalho. O mesmo procedimento foi realizado com os microdados provenientes do Instituto Brasileiro de Geografia e Estatística (IBGE), para

${ }_{2}$ Considerando, respectiva e cronologicamente os anos eleitorais analisados, os números de classificações diferentes são: 102, 113 e 74 .

3 Os agrupamentos ocupacionais são os que seguem: Administradores, Diretores e Gerentes; Agricultores, Pecuaristas, etc.; Comerciantes, Empresários, Servidores Públicos em Geral (todos os níveis, inclusive aposentados); Funcionários e Trabalhadores em geral; Médicos; Engenheiros; Advogados; Ocupantes de cargo público eletivo ou por comissão (todos os níveis); Outros ou em ocupações mal definidas; Outros profissionais com titulação universitária (exceto médicos, advogados, engenheiros e professores universitários); Professores de Ensino Fundamental e Médio; Militares em geral e Professores Universitários. 
os quais foram consideradas as especificações presentes no Código Brasileiro de Ocupações $\left(\mathrm{CBO}^{4}\right)$, de modo a proceder a padronização das classificações ocupacionais para o conjunto dos dados estatísticos disponíveis.

Por se tratar da apreensão de um conjunto de condicionantes que são parte de lutas específicas, o uso das classificações ocupacionais de origem, como modos de apresentação e de autodefinição de uma posição social, não prescinde as lógicas e razões de ser da produção e divulgação dos registros oficiais. Portanto, as definições categoriais expostas nas fichas de candidaturas remetem tanto aos esquemas "práticos" de classificação social, quando ao espaço de posições e disputas político-eleitorais, mobilizando "uma série de transações entre diversas representações da realidade social” (MERLLIÉ, 1996, p. 163).

Ademais, como destacado por Offerlé (1999, p. 20-8), os usos da condição profissional de origem em sua relação com a "entrada na profissão política" representam a adesão, negação ou naturalização de determinadas referências sociais. Consequentemente, as modalidades de "reconversão" de classificações profissionais em recursos nestas lutas são variadas, remetendo ora a "títulos" socialmente mais valorizados, e que indicam posições sociais e escolares hierarquicamente mais elevadas, ora ao funcionando como "estratégias de condescendência" (BOURDIEU, 1990, p. 154), vinculadas à denegação da posição social de origem em prol das respectivas retribuições derivadas deste processo.

Portanto, estão em pauta as condições sociais de participação na concorrência eleitoral, de modo a explicitar o conjunto de princípios de classificação e hierarquização social que se estendem à "concorrência política" (GAXIE, 1980, p. 6). O cotejo entre os recursos de posição social e as características sociais dos candidatos a cargos legislativos no Rio Grande do Sul, evidencia a rentabilidade política dos "títulos" e posições frente às lutas pela ocupação dos postos de representação política, assim como os princípios de hierarquização subjacentes à concorrência eleitoral. De modo mais geral, trata-se da evidenciação das relações práticas com determinadas classificações sociais resultantes da objetivação da concorrência pelos cargos e da imposição dos critérios de entrada e reprodução fundadas em determinados princípios de hierarquização e de excelência social.

4 <http://www.mtecbo.gov.br/cbosite/pages/home.jsf> 


\section{CATEGORIAS SOCIOPROFISSIONAIS, TITULAÇÃO ESCOLAR E CHANCES DE ATUAÇÃO COMO CANDIDATO}

Uma primeira observação acerca da relação entre a representatividade de determinadas categorias no espaço social e sua comparação com as características socioprofissionais dos agentes inseridos nas disputas eleitorais oferece o esboço inicial das relações entre a estrutura social e a estrutura do espaço de disputas eleitorais do Rio Grande do Sul, no período analisado. Os índices de representação5 indicam a maior probabilidade de que determinadas categorias socioprofissionais sejam encontradas entre o conjunto dos candidatos a cargos legislativos no período em pauta. Esta estrutura geral de recrutamento explicita três modalidades de relação com a "política". Primeiramente, a associação mais evidente de empresários, médicos, engenheiros e advogados com o espaço de disputas político-eleitorais é tributário dos princípios de hierarquização e excelência social subjacentes aos processos de seleção política. Ou seja, as categorias melhor representadas entre o conjunto de candidatos remetem a posições sociais mais elevadas, a relações específicas com a divisão social do trabalho e a "competências técnicas" e "sociais" estatutariamente garantidas e legitimadas pelas burocracias públicas. Em segundo lugar, o destaque aos ocupantes de cargo público eletivo ou por comissão põe em evidência o peso do exercício prévio de "funções" na burocracia pública como recurso na participação eleitoral. Isso se deve ao "carisma de função" e ao peso do exercício prévio de atividades de "mediação" das relações entre "estado" e "sociedade" nas lutas político-eleitorais (CORADINI, 2001, 2010). Por fim, a alta porcentagem de candidatos com ocupações não classificáveis ou em classificações mal definidas, e a consequente representatividade destes frente ao conjunto da população, aponta para um processo de diversificação, omissão e/ou manipulação das classificações ocupacionais de origem com vistas à legitimação ou negação de determinadas atividades frente às finalidades práticas de produção dos registros oficiais.

\footnotetext{
${ }^{5} \mathrm{O}$ índice de representação das categorias ocupacionais é calculado a partir do modelo proposto por GAXIE (1980), cuja formula é: \% dos parlamentares de determinada categoria / \% da população ativa da mesma categoria x 100 = Índice de Representação
} 
Tabela 1

Categorias socioprofissionais e índices representação na concorrência eleitoral

\begin{tabular}{|c|c|c|c|}
\hline & 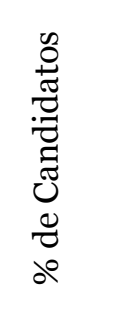 & 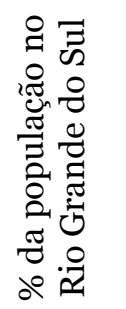 & 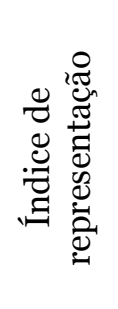 \\
\hline Administradores, Diretores e Gerentes & $1,7 \%$ & $5 \%$ & 20 \\
\hline Agricultores, Pecuaristas, etc. & $2,8 \%$ & $18,3 \%$ & 15 \\
\hline Comerciantes & $5,2 \%$ & $7,9 \%$ & 66 \\
\hline Empresários & $5,8 \%$ & $0,7 \%$ & 828 \\
\hline Servidores Públicos em Geral & $8,1 \%$ & $5,5 \%$ & 147 \\
\hline Funcionários, Técnicos e Trabalhadores em Geral & $9,6 \%$ & $58,5 \%$ & 16 \\
\hline Médicos & $4,5 \%$ & $0,4 \%$ & 1125 \\
\hline Engenheiros & $3,5 \%$ & $0,2 \%$ & 1750 \\
\hline Advogados & $10 \%$ & $0,5 \%$ & 2000 \\
\hline Ocupante de cargo público eletivo ou por comissão (todos os níveis) & $14,8 \%$ & $0,3 \%$ & 4933 \\
\hline Outros ou em ocupações mal definidas & $16,3 \%$ & $0,7 \%$ & 2328 \\
\hline Outros profissionais com titulação universitária & $7,1 \%$ & $2,5 \%$ & 284 \\
\hline Professores de Ensino Fundamental e Médio & $6,5 \%$ & $3,3 \%$ & 196 \\
\hline Militares em Geral & $3,3 \%$ & $1,4 \%$ & 235 \\
\hline Professores Universitários & $0,8 \%$ & $0,3 \%$ & 266 \\
\hline
\end{tabular}

Fonte: Censo/IBGE - 2000. Registros de Candidatura - TRE-RS.

Como destacado por Gaxie (1980), o recrutamento parlamentar apresenta uma "imagem invertida" da estrutura social, configurando uma sobrerrepresentação das "camadas mais altas" e uma sub-representação das "mais baixas". Esta constatação mais geral indica, em parte, a estrutura do espaço de concorrência eleitoral no Rio Grande do Sul, de modo que é possível notar a concentração significativa do recrutamento de candidatos a cargos legislativos em determinadas categorias ocupacionais que representam posições sociais mais altas, tais como: empresários; médicos; engenheiros e advogados.

Ocorre que, mais do que constatar a "osmose" entre determinadas categorias socioprofissionais e o espaço de concorrência eleitoral (DOGAN, 1999, p. 173), trata-se 
de especificar a relação disso com os indicadores em pauta, evidenciando os significados sociais destas diferenciações e seu peso na participação ativa em eleições. Em outros termos, mesmo que haja uma legitimidade prévia e um conjunto mais ou menos articulado de representações sociais acerca das ocupações em pauta e para que posições sociais estas remetem, o que interessa aqui são os fundamentos sociais presentes no processo de hierarquização e as estruturas objetivas que engendram, legitimam e produzem as diferenças frente à concorrência eleitoral. Como parece evidente, estas estruturas objetivas só podem ser apreendidas a partir do conjunto de variáveis que definem as relações entre determinadas categorias socioprofissionais no espaço social global e sua respectiva hierarquização frente ao espaço de concorrência eleitoral.

De tal modo, as chances de especialização em atividade política variam de acordo com a posse desigual dos instrumentos materiais e culturais necessários à participação ativa na política, entre os quais, os mais significativos são o "capital econômico" e o "capital cultural". Ou seja, os mecanismos sociais, que são o fundamento da divisão entre "profissionais" e "profanos", variam de acordo com o "volume global do capital econômico e cultural” e, também, “em função da estrutura, mais ou menos dissimétrica" de sua distribuição (BOURDIEU, 2007a, p. 164-5). Para a presente exposição, o "capital econômico" é definido a partir do montante de rendimentos do trabalho principal, o que define a posição de determinadas categorias relativas à estrutura de "classes". Do mesmo modo, o "capital cultural" é apreendido a partir da titulação escolar.

Considerando as relações entre rendimentos do trabalho principal e categorias socioprofissionais, ocorre uma relação acentuada entre aquelas categorias com maiores montantes de rendimentos e a participação eleitoral. Isso fica mais evidente ao tomar os casos mais extremos e que polarizam as chances de participação nas eleições, neste caso, os agricultores, pecuaristas, etc., e os funcionários, técnicos e trabalhadores em geral, com menos chances de participação eleitoral, e, no extremo oposto, os empresários, médicos, engenheiros e advogados. De um modo mais específico, as variações em termos de índices de representação e rendimentos do trabalho principal relativamente a estas categorias são diretamente proporcionais, ou seja, menor rendimento indica menor representação entre o conjunto de candidatos, e vice-versa.

As associações mais diretas do polo de menor participação eleitoral se dão com os níveis de rendimento de um a três salários mínimos para os funcionários, técnicos e trabalhadores em geral (56,3\% contra $46 \%$ do conjunto do universo), e dos sem rendimentos para os agricultores, pecuaristas, etc. (40,8\% contra 9,3\% do conjunto do universo). Ao contrário, para aquelas categorias com maiores chances de ingresso nas 
disputas por cargos eletivos, as associações mais fortes se dão com os valores de rendimentos mais elevados, tais como aquele entre dez e vinte salários mínimos para empresários, engenheiros e advogados (respectivamente, 28,6\%, 36,6\% e 26,4\% contra $4 \%$ do conjunto do universo), e aquele maior de trinta salários mínimos de rendimentos para os médicos (20,5\% contra 0,7\% do conjunto do universo). Além disso, para este último nível de rendimento, ocorre também uma forte associação com as categorias dos empresários e advogados (respectivamente, 11,8\% e 11,7\% contra 0,7\% do conjunto do universo).

Se por um lado as possibilidades de atuação como candidato em eleições gerais variam de acordo com os rendimentos do trabalho principal, ocorre, igualmente, uma associação entre as chances de participação ativa na política e o grau de escolaridade. $O$ peso da titulação escolar é tão mais significativo na hierarquização das chances de ingresso na concorrência eleitoral quanto mais está associado ao montante de rendimentos econômicos. Ou seja, quanto mais positivamente variam, maiores as chances de atuação nas disputas eleitorais.

A diferenciação progressiva com base nas relações entre recursos sociais e chances de acesso a um domínio de atividades especializadas constitui a separação entre "profissionais" e "profanos", cuja realidade prática se expressa na imposição da problemática legítima e de um savoir-faire especializado, irredutível às demais formas de atuação social. Deste modo, a relação entre a condição socioeconômica e a inserção na competição por cargos de representação política fundamenta as condições de legitimidade frente à esfera eleitoral. Contudo, via de regra, não existe nenhum tipo de relação intrínseca entre o sucesso econômico e o sucesso político, sendo que as condições de reconversão do primeiro em "legitimidade política" dependem do trabalho social de mobilização e imposição deste como competência socialmente legítima e reconhecida frente ao espaço político-eleitoral. Neste sentido, entram em pauta as diferentes possibilidades de mobilização e manipulação de determinados princípios de classificação e excelência social com vistas à imposição de um conjunto de recursos e competências como eleitoralmente relevantes.

Sob esta perspectiva, as condições de acesso à problemática específica relativamente à concorrência eleitoral dependem das possibilidades objetivas de "dar sentido às lutas", o que varia de acordo com o capital escolar. Trata-se da desigual distribuição de uma competência "técnica" como "aptidão para operar classificações", a qual "depende, fundamentalmente, da competência social e do sentimento correlato de ser estatutariamente fundamentado e convocado a exercer essa capacidade específica”. Deste modo, a competência técnica garantida pelo diploma escolar é, ao mesmo tempo, "uma condição de exercício" e “um efeito” social (BOURDIEU, 2007b, p. 382-3). 
O aumento proporcional das chances de ingresso na concorrência eleitoral com o aumento da titulação escolar indica a concentração das chances de ingresso na política nas mãos de um pequeno grupo de "profissionais". Portanto, as condições de entrada, constituição e afirmação de especialistas em atividade política são evidências da "imposição da linha" e da definição do conjunto de recursos sociais necessários a participação eleitoral. Trata-se a explicitação da realidade objetiva de um espaço estruturado por determinados critérios de entrada, o que torna mais explícitos os princípios de hierarquização social que estão na base da seleção política.

Como se pode notar, o peso do grau de escolaridade de ensino superior completo é muito significativo para o conjunto dos candidatos, indicando um princípio de hierarquização frente às chances de atuação na concorrência eleitoral de acordo com a desigual distribuição do capital escolar no conjunto das categorias socioprofissionais. Isso se reflete, principalmente, nas oposições que estruturam as chances de que determinados agentes sociais se apresentem como candidatos e sejam reconhecidos enquanto tais. Mais associados às possibilidades de participação ativa na "política" estão aqueles com grau de escolaridade de ensino superior completo, indicando a posição mais extrema com relação às chances de participação eleitoral. Em segundo lugar, ocorre uma associação mais evidente com o ensino superior incompleto e, embora com menos intensidade, com o ensino médio incompleto e completo, especificando diferentes condições de acesso a concorrência eleitoral relativamente a determinados graus de titulação escolar.

Tabela 2: Titulação escolar e chances de atuação na concorrência eleitoral

\begin{tabular}{|c|c|c|c|}
\hline & 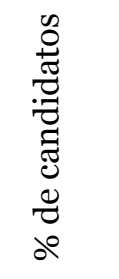 & 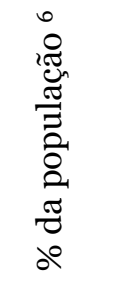 & 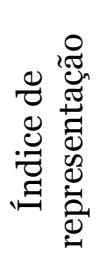 \\
\hline $\begin{array}{l}\text { Sem instrução ou menos de um ano de } \\
\text { escolarização }\end{array}$ & $0,3 \%$ & $4,9 \%$ & 6 \\
\hline Ensino fundamental incompleto & $5,4 \%$ & $34,8 \%$ & 15 \\
\hline Ensino fundamental completo & $5,2 \%$ & $7,4 \%$ & 70 \\
\hline Ensino médio incompleto & $5,6 \%$ & $3,9 \%$ & 143 \\
\hline Ensino médio completo & $15,5 \%$ & $9,9 \%$ & 156 \\
\hline Ensino superior incompleto & $15,3 \%$ & $3,1 \%$ & 493 \\
\hline Ensino superior completo & $52,7 \%$ & $4,3 \%$ & 1225 \\
\hline
\end{tabular}

Fonte: Censo/IBGE - 2000. Registros de candidaturas - TRE-RS

\footnotetext{
${ }^{6}$ A soma das porcentagens resulta no total de $68,3 \%$, compreendendo a população maior de 18 anos com as respectivas titulações escolares.
} 
A “duração da escolarização" está intimamente ligada ao conjunto de condições de possibilidade de sua realização, e aparece como um dos principais indicativos da desigual distribuição da "politização" entre as classes sociais (GAXIE, 1987). Nestes termos, os diferentes graus de titulação escolar e a comparação entre o conjunto das categorias e a condição ocupacional de origem dos candidatos especificam os mecanismos sociais de divisão do trabalho político e as diferentes estruturas de capital associadas às chances de participação eleitoral distribuídas por categorias socioprofissionais. Isso quer dizer que as lógicas de seleção política são retraduzidas para o interior das diversas categorias em pauta, visto que os candidatos são recrutados, normalmente, de acordo com determinadas condições sociais que variam com relação à desigual distribuição dos recursos de posição social no interior das diversas ocupações profissionais.

Tabela 3: Categorias socioprofissionais e ensino superior completo

\begin{tabular}{|c|c|c|}
\hline & 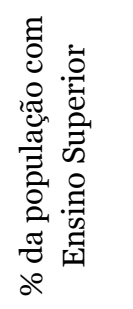 & 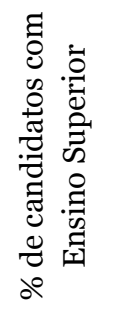 \\
\hline Administradores, Diretores e Gerentes & $20 \%$ & $67,6 \%$ \\
\hline Agricultores, Pecuaristas, etc. & $0,7 \%$ & $16,7 \%$ \\
\hline Comerciantes & $3 \%$ & $5,9 \%$ \\
\hline Empresários & $26,4 \%$ & $31 \%$ \\
\hline Servidores públicos em geral & $30,3 \%$ & $52,5 \%$ \\
\hline Funcionários, Técnicos e Trabalhadores em Geral & $2,7 \%$ & $19,6 \%$ \\
\hline Médicos & $96,8 \%$ & $100 \%$ \\
\hline Engenheiros & $81 \%$ & $98,6 \%$ \\
\hline Advogados & $93,6 \%$ & $99 \%$ \\
\hline Ocupante de cargo público eletivo ou por comissão (todos os níveis) & $33,7 \%$ & $51,9 \%$ \\
\hline Outros ou em ocupações mal definidas & $16 \%$ & $17,9 \%$ \\
\hline Outros profissionais com titulação universitária & $59,9 \%$ & $87,1 \%$ \\
\hline Professores de ensino fundamental e médio & $45,5 \%$ & $91,4 \%$ \\
\hline Militares em geral & $8,8 \%$ & $38,5 \%$ \\
\hline Professores universitários & $90,9 \%$ & $100 \%$ \\
\hline
\end{tabular}

Fonte: Censo/IBGE - 2000. Registros de candidatura - TRE-RS.

Este processo, de concentração das chances de atuação como candidato em eleições gerais baseado na posse diferenciada de titulação escolar e, mais especificamente, da titulação escolar mais elevada, tem como decorrência o fato de que o ingresso na condição de candidato, em quase todas as categorias, se realiza nos 
segmentos mais escolarizados das mesmas. Isso indica que as chances de delegação das funções de representação política são inversamente proporcionais a posse de títulos escolares mais elevados, sendo que, ocorre uma extensão deste mecanismo social de divisão do trabalho político para o interior das categorias socioprofissionais e agrupamentos em pauta. A importância do capital escolar para a atuação como candidato em eleições gerais ocasiona uma aproximação entre as ocupações de origem dos candidatos e o polo escolarmente dominante (Ilustração 1).

Ilustração 17: Categorias socioprofissionais, titulação escolar e seleção política ${ }^{8}$

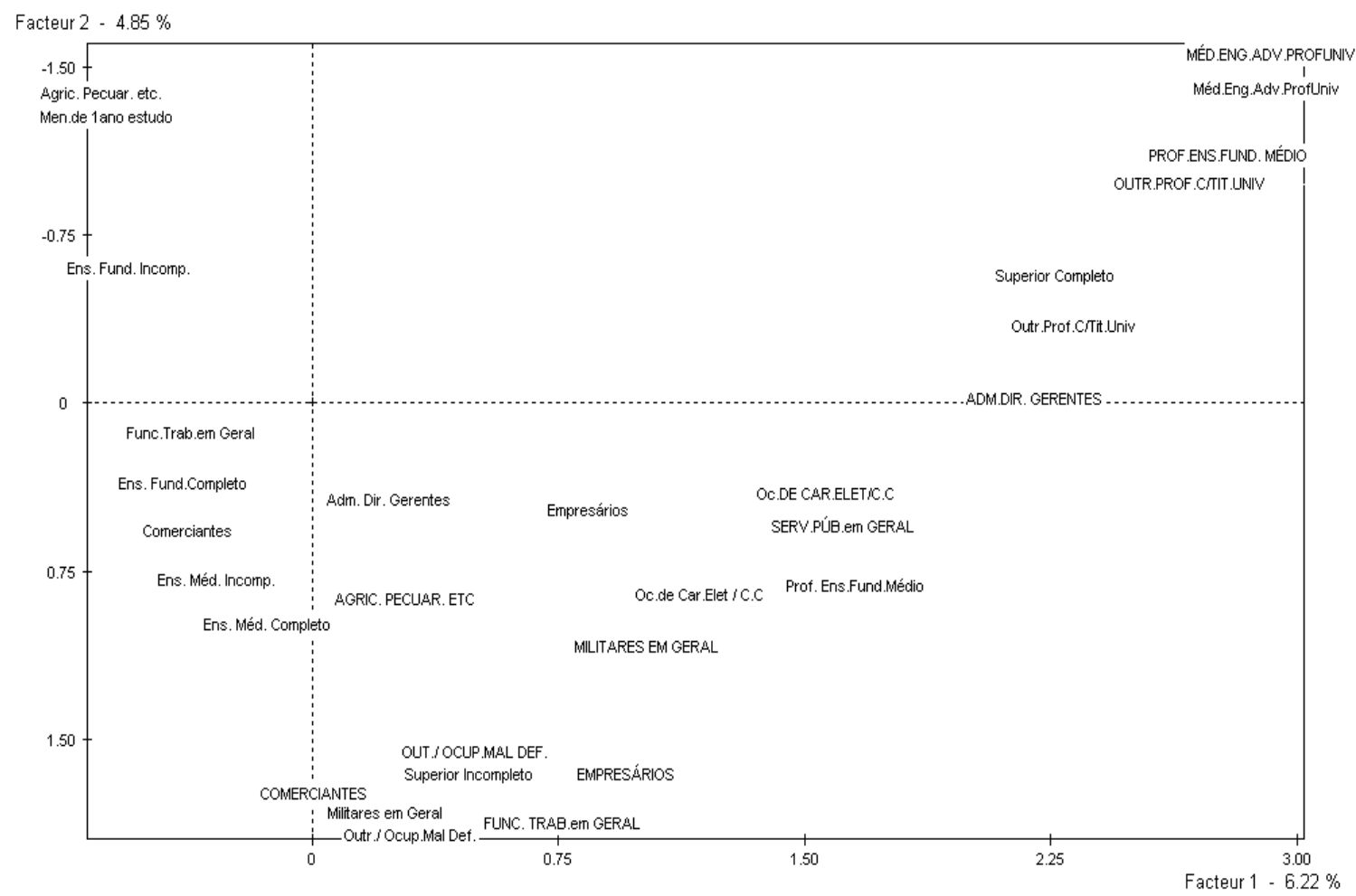

Fonte: PNAD/IBGE - 2002. Registros de candidaturas - TRE-RS.

\footnotetext{
$7 \mathrm{O}$ eixo do primeiro fator tem como resultante um valor próprio de 0,8709 e inércia total de 6,22\%. A contribuição das variáveis é simétrica na formação dos eixos, variando o peso relativo às modalidades. Dentre estas, as que mais contribuem para a constituição do primeiro eixo estão os graus de titulação escolar de superior completo (39,24\%) e de ensino fundamental incompleto (7,44\%); e as categorias socioprofissionais de médicos, engenheiros, advogados e professores universitários para o conjunto da população $(7,34 \%)$ e para os candidatos (10,88\%). O segundo fator tem como resultante um valor próprio de 0,6784, e explica 4,85\% (inércia) da tendência de deslocamento e realocação das "nuvens". As modalidades que mais contribuem para a formação deste fator são a titulação escolar de ensino médio completo (12,65\%), ensino superior incompleto (13,75\%) e ensino fundamental incompleto (11,48\%). Para as classificações ocupacionais, as que mais contribuem são as dos agricultores, pecuaristas, etc. para o conjunto da população (21,85\%). O terceiro fator tem como resultante um valor próprio de 0,5777 e inércia total de 4,13\%. As modalidades que mais contribuem para a constituição deste fator são o grau de escolarização de ensino superior incompleto $(28,89 \%)$ e o ensino médio completo $(8,24 \%)$. No caso das categorias socioprofissionais, as que mais contribuem são as dos outros ou em ocupações mal definidas $(9,66 \%)$ e dos agricultores, pecuaristas, etc. $(11,22 \%)$ para o conjunto da população.
}

${ }^{8}$ As categorias ocupacionais de origem dos candidatos são expressas pela nomenclatura em caixa alta. 
As evidências mais significativas das diferenciações na relação entre capital escolar, categorias socioprofissionais e chances de atuação como candidatos são indicadas pelas oposições entre o conjunto das categorias e os segmentos encarregados de disputar os cargos de representação política. As principais diferenciações quanto a isso se dão para os agricultores, pecuaristas, etc., os funcionários, técnicos e trabalhadores em geral, os professores de ensino fundamental e médio e os administradores, diretores e gerentes, condições ocupacionais de origem dos candidatos que indicam maior distanciamento do conjunto das categorias em geral, relativamente ao recurso em pauta.

Ao contrário, as diferenciações menos significativas entre ponto de partida dos candidatos e o conjunto das categorias se dão, em primeiro lugar, com as classificações ocupacionais para as quais a posse de titulação universitária é condição de exercício profissional. Por outro lado, ocorre igualmente uma diferenciação não significativa com relação aos empresários, aos comerciantes e aos outros ou em ocupações mal definidas, sendo que os candidatos com estas ocupações de origem, em geral, não se diferenciam de modo significativo quanto à titulação escolar do conjunto das categorias em pauta.

As diferentes relações entre graus de titulação escolar e as disputas por cargos eleitoralmente em jogo evidenciam, de modo significativo, a posse de níveis hierarquicamente mais altos de capital escolar como condição de garantia de legitimidade frente ao espaço eleitoral. As consequências desta concentração são mais evidentes ao confrontar os recursos escolares com os econômicos, indicando uma probabilidade associada às chances de participação eleitoral diretamente proporcional ao volume de rendimentos e de titulação escolar.

Deste modo, as chances de participação eleitoral estão condicionadas, em primeiro lugar, pela posse de montantes mais altos de recursos sociais específicos, notadamente, de rendimentos econômicos e titulação escolar. Em segundo lugar, entra em pauta uma associação mais direta com a distribuição dissimétrica dos diferentes recursos de posição social, os quais, dentro dos limites e possibilidades de comparação do material empírico utilizado, indicam um peso significativo do capital escolar na inserção em eleições como candidato. A concentração das chances de atuação como candidatos nas posições escolarmente, mas também economicamente dominantes, impõem um distanciamento objetivo entre o conjunto das categorias socioprofissionais e o espaço de concorrência eleitoral, indicando o peso de determinadas condições sociais e escolares prévias a atuação como candidato como princípio determinante nas chances de inserção eleitoral. 


\section{CONSIDERAÇÕES FINAIS}

Como exposto anteriormente, o presente texto tinha por objetivo problematizar algumas relações entre determinados recursos de posição social e as chances de participação eleitoral na condição de candidato. Evidentemente, se tratam de associações estatísticas e indicam apenas algumas tendências gerais no que tange as probabilidades de que determinadas categorias socioprofissionais sejam utilizadas como recursos de apresentação e/ou legitimação da condição de candidato aos cargos de representação política. Contudo, estas indicações mais gerais dos princípios de hierarquização e excelência social presentes nas disputas eleitorais merecem ser especificadas com analises mais detalhadas das diferentes lógicas de ação e recursos que podem ser mobilizados em situações históricas e sociais específicas.

Entretanto, algumas indicações acerca das diferentes possibilidades de reconversão de "legitimidade social" em "legitimidade política" (GAXIE, 1980) podem ser expostas de modo mais geral. A primeira delas está diretamente relacionada à forte associação entre as classificações socioprofissionais que indicam posições econômicas mais elevadas e as chances de atuação como candidatos. Isso indica, de modo mais específico, certo tipo de "plutocratismo" presente no processo de hierarquização social e sua respectiva relação com princípios e critérios de excelência social requeridas pelo processo eleitoral.

A outra constatação mais geral sobre as relações entre determinados recursos de posição social e as chances de candidatura é o peso significativo da titulação escolar na divisão do trabalho de representação política, o que se expressa diretamente no distanciamento objetivo entre determinadas categorias socioprofissionais e o espaço de concorrência eleitoral. Ao mesmo tempo, ocorre uma hierarquização interna a estas categorias com base nas diferentes relações com as titulações escolares mais elevadas, o que indica que as lógicas de seleção política se retraduzem internamente as categorias em pauta.

Por fim, as indicações presentes neste esboço geral de relações mais detalhadamente analisadas em outro trabalho (BORDIGNON, 2011) apontam para determinadas estruturas de recursos sociais e suas associações com o espaço de concorrência eleitoral. As principais decorrências disso são as indicando de que as dinâmicas da concorrência eleitoral se inscrevem na realidade prática dos processos de luta pela conquista de determinados cargos definidos como políticos e, de modo mais direto, isso serve de fundamento para o conjunto de princípios de dominação e reprodução social inscritos nessas lutas. 


\section{REFERENCIAS BIBLIOGRAFICAS}

AGRIKOLIANSKY, Éric. Biographies d'institution et mise en scène de l'intellectuel. Les candidats au comité central de la LDH. Politix. Revue des sciences sociales du politique, n. 27, 1994.

BEST, H. e GAXIE, D. 200o. Detours to modernity: long-term trends of parliamentary recruitment in republican France 1848-1999. In: Best, H. e Cotta, M. (eds.).

Parlamentary Representatives in Europe 1848-200o; Lesgislative recruitment and careers in eleven European countries. Oxford, Oxford University Press, p. 88-137.

BORDIGNON, Rodrigo da Rosa. Recursos sociais e modalidades de entrada na política: Recrutamento e seleção de elites políticas no Rio Grande do Sul entre 1998 e 2006. Dissertação de mestrado apresentada ao PPGCP/UFRGS. Porto Alegre, 2011.

BOURDIEU, Pierre. Coisas Ditas. SP: Brasiliense, 1990.

- A representação política: elementos para uma teoria do campo

político. In: . O Poder Simbólico. Rio de Janeiro: Bertrand

Brasil, 2007a.

. A distinção: crítica social do julgamento. Porto Alegre: Zouk,

$2007 \mathrm{~b}$.

Classificação, desclassificação, reclassificação. In:

CATANI, Afrânio. NOGUEIRA, Maria Alice. (orgs). Escritos de Educação: Pierre Bourdieu. Petrópolis, RJ: VOZES, 2007c, p. 145-84.

BOLTANSKY, Luc et BOURDIEU, Pierre. O diploma e o cargo : relações entre o sistema de produção e o sistema de reprodução. In: CATANI, Afrânio. NOGUEIRA, Maria Alice. (orgs). Escritos de Educação: Pierre Bourdieu. Petrópolis, RJ: VOZES, 2007. p. 12744 .

CORADINI, Odaci Luiz. Em nome de quem? Recursos sociais e Recrutamento de Elites políticas. Rio de Janeiro: Relume Dumará, 2001.

Representação profissional e elites políticas no Brasil no

período recente. Politica \& Sociedade, v. 5, $n^{\circ}$ 9, 2006, p. 123-61.

. Engajamento associativo-sindical e recrutamento de elites políticas: tendências recentes no Brasil. Revista de Sociologia e Política, Curitiba, $\mathrm{n}^{0} 28,2007$.

L'Enseignement Universitaire de Théologie, les Rapports Centre/Péripherie e les Usages des Sciences Humaines et Sociales. Cahiers de la Recherche sur l’Éducation et les Savoirs, v. 2, 2009, p. 93-116

Categorias Sócio-Profissionais, Titulação Escolar e

Disputas Eleitorais. Revista de Sociologia e Política, Curitiba, 2010. (a sair)

DÉLOYE, Yves. Se présenter pour représenter. Enquête sur les professions de foi électorales de 1848. In: OFFERLÉ, Michel (eds.). La Profession Politique; XIXeXXe siècles. Paris : Éditions Belin, 1999, p.231-54. 
DOGAN, Mattei. Les profession propicces à la carrière politique. Osmoses, filières e viviers. In: OFFERLÉ, Michel. (eds.). 1999. La Profession Politique; XIXe-XXe siècles. Paris, Éditions Belin, p. 171-99.

DULONG, Delphine. Quand l'économie devient politique. La conversion de la compétence économique en compétence politique sous la Ve République Politix.

Revue des sciences sociales du politique, Année 1996, Volume 9, Numéro 35, p. 109-30.

GAXIE, Daniel. Les logiques du recrutement politique. Revue française de science politique, Année 1980, Volume 30, Numéro 1, p. 5- 45.

Les facteurs sociaux de la carrière gouvernamentale sous la

Cinquième République de 1959 à 1981. Revue française de sociologie, Année 1983, Volume 24, Numéro 3, p. 441-65.

. Le cens caché. Réseaux. Communication - Technologie Société, Année 1987, Volume 5, Numéro 22, p. 29-51.

LACROIX, Bernard. Ordre Politique et ordre social : objetivisme, objetivation et analyse politique. In : GRAWITZ, M. \& LECA, J. (dir.). Traité de Science Politique : L’ordre politique. V. 1, Paris : Presses Universitaires de France, 1985. p. 469-565.

LAGROYE, Jacques. Sociologie Politique. Paris: Presse de Sciences Po Dalloz, 1993.

LÉVÊQUE, Sandrine. «L'entrée en politique». Bibliographie sur les conditions sociales de la professionnalisation et de la «réussite» politique en France. Politix. Revue des sciences sociales du politique, Année 1996, Volume 9, Numéro 35, p. 171-87.

LOWI, Theodore. O Estado e a Ciência Política ou como nos convertemos naquilo que estudamos. BIB 38, 1994.

MERLLIÉ, Dominique. Les categories socio-professionelles et es conditions de leus mise en oeuvre. Actes de la Recherche en Sciences Sociales, (50), 1983.

A construção estatística. In: CHAMPAGNE, Patrick. et all.

Iniciação à prática sociológica. Rio de Janeiro: Vozes, 1996.

OFFERLÉ, Michel. Entrées en politique (Présentation). Politix. Revue des sciences sociales du politique, Année 1996, Volume 9, Numéro 35, p. 3-5.

Professions et profession politique. In:

(eds.). La Profession Politique; XIXe-XXe siècles. Paris : Éditions Belin, 1999, p. 7-35.

SAWICKI, Frédéric. Classer les homes politiques. Les usages des indicateurs de position sociale por la comprehension de la professionalization politique. In:

OFFERLÉ, Michel. (eds.). 1999. La Profession Politique; XIXe-XXe siècles. Paris, Éditions Belin, 1999, p. 93-134.

WEBER, Max. A política como vocação. In: Ciência e Política: duas vocações. São Paulo: Martin Claret, 2003. p. 59-124.

WILLEMEZ, Laurent. La « République des avocats ». 1848 : le mythe, le modèle et son endossement. In: OFFERLÉ, Michel. (eds.). 1999. La Profession Politique; XIXeXXe siècles. Paris, Éditions Belin, 1999, p. 201-30.

ZARCA, Bernard. Les patrons dans la statistique officielle française. In: Politix:

Revue des sciences sociales du politique, 23, 1993, p. 44-65. 